\title{
Effects of Drying Methods Based on Exhaust Cycle and Time on the Quality and Drying of Red Peppers
}

\author{
Sang Heon $\mathrm{Nam}^{1}$, Yu Shin $\mathrm{Ha}^{1}$, Tae Wook $\mathrm{Kim}^{2}$ * \\ ${ }^{1}$ Department of Bio-Industrial Machinery Engineering, Kyungpook National University, Daegu, Korea \\ ${ }^{2}$ Department of Precision Mechanical Engineering, Kyungpook National University, Sangju, Korea \\ Received: March 25 $5^{\text {th }}$ 2014; Revised: April $22^{\text {nd }} 2014$; Accepted: May $16^{\text {th }} 2014$
}

\section{Abstract}

Purpose: The purpose of this study is to develop a system to optimize drying potential energy of the exhausted hot air by changing relative humidity of the air. This study modified the conventional drying method into a drying method changing exhaust cycle and time in order to control the relative humidity of the exhausted hot air during drying process. Method: A valve on the vent was controlled according to a preset time to change the exhaust cycle and time. This study analyzed the influence of the two different types of drying method on the drying characteristics, required energy, and quality of the dried peppers: conventional drying method exhausting hot air continuously and new drying method controlling exhaust cycle and time. Results: Drying characteristics based on exhaust time showed that drying time increased with exhaust time, and specific energy consumption was reduced by $28 \%$ from $18.39 \mathrm{MJ} / \mathrm{kg}$ (conventional method) to $13.24 \mathrm{MJ} / \mathrm{kg}$ when exhaust time was set to one minute. Drying characteristics based on heating time showed that drying time increased with heating time and specific energy consumption was reduced by $30 \%$ from $18.39 \mathrm{MJ} / \mathrm{kg}$ (conventional method) to $12.87 \mathrm{MJ} / \mathrm{kg}$ when exhaust time was set to 22 minutes. Drying characteristics based on exhaust cycle showed that drying time increased with exhaust cycle, and specific energy consumption was reduced by $31 \%$ from $18.39 \mathrm{MJ} / \mathrm{kg}$ (conventional method) to 12.69 $\mathrm{MJ} / \mathrm{kg}$ when exhaust time was set to one minute and exhaust cycle was set to 22 minutes before drying and 40 minutes after drying. The quality of the dried red peppers showed that capsaicin, color, and sugar content were high as $34.87 \mathrm{mg} / 100 \mathrm{~g}$, 66.33 , and $11.87 \%$, respectively, when exhaust time was set to one minute and exhaust cycle was set to 22 minutes before drying and 40 minutes after drying. Conclusions: In order to utilize the drying potential energy of the exhausted air during drying process, the conventional drying method was modified into the drying method controlling exhaust cycle and time. The results showed that drying with exhaust cycle of one minute was more efficient in terms of drying time, required energy, and quality of the dried peppers than the one with exhaust cycle of 20 40 minutes.

Keywords: Capsaicin, Drying potential energy, Humidity, Page model, Specific energy consumption

\section{Introduction}

Hot air drying, which transfers thermal energy to the material to be dried by contacting the hot air on the material, is popular for drying red peppers. The supplied hot air with low humidity induces water evaporation through thermal transfer by contacting on the red peppers which is low in temperature and high in moisture content.

\footnotetext{
*Comesponding author: Tae Wook Kim

Tel: +82-54-530-1277; Fax: +82-54-530-1277

E-mail: kimtw@knu.ac.kr
}

The supplied hot air increased humidity by the evaporated moisture from peppers, and the humid air is exhausted through the vent.

The red pepper has high moisture content, but the moisture evaporates fast at the initial stage of the hot air drying. Therefore, highly efficient energy utilization is possible because the heated air with high humidity is exhausted outside as much as drying potential energy. However, the moisture content of the red pepper is reduced at the late stage of drying process, and the moisture does not evaporate as much as the drying potential 
energy of the heated air. The energy is not used efficiently in that the heated air having the available energy for evaporating the moisture in red peppers is exhausted and wasted (Moon et al., 1999).

The humidity as well as temperature of drying air is important in terms of the utilization of energy. However, previous research on drying characteristics and quality of red peppers has focused on the drying temperature: a study with different drying temperature from $55^{\circ}$ to $80^{\circ}$ (Kim et al., 1975), studies with different drying methods such as hot air drying, far-infrared radiation assisted drying, and freeze drying (Koh et al., 1989; Chung et al., 2003), studies with cut or perforated red peppers (Kim et al., 1975; Yoon and Lee, 2004), and studies with different heat source such as electric heat and solar heat (Park, 1975; Yoon et al., 1999). Koh et al. (1987) tried drying red peppers by setting the temperature and relative humidity of the chamber. Their study was conducted with constant relative humidity, but the pepper dryer for farmers cannot maintain a constant humidity due to the changes of relative humidity with drying time.

In addition, a heat recovery system using a heat exchanger was designed to utilize the exhausted hot air (Back et al., 2002), but the size and price of the device was not affordable.

The purpose of this study is to develop a system to optimize drying potential energy of the exhausted hot air by changing relative humidity of the air. For that purpose, the conventional drying method was modified into the system changing exhaust cycle and time. And then the influence of the drying methods on drying characteristics, drying energy, and quality of the dried peppers were analyzed.

\section{Materials and Methods}

\section{Materials}

Yeongyangmat, a variety of red pepper, grown in 2011 at Naju, Jeonnam Province was used for this study. The average length of the red pepper was $124.56 \mathrm{~mm}$, and the average diameter of it was $19.44 \mathrm{~mm}$ (longest) and 16.9 $\mathrm{mm}$ (shortest). And average weight of it was $18.76 \mathrm{~g}$. The initial moisture content was $83.5 \sim 84.5 \%$ (w.b.) which was measured with Infrared moisture meter (FD-720, Kett, Japan). $3.75 \mathrm{~kg}$ of red peppers was dried in one experiment.

\section{Electric dryer blowing hot air}

Figure 1 shows the structure of the electric dryer blowing hot air fabricated for this study, and a control algorithm was configured to control the drying time with continuous exhaust mode or periodic exhaust mode. Three modes of internal air flow were determined for the experiment: (a) internal circulation mode, (b) continuous exhaust mode, (c) periodic exhaust mode. Internal circulation mode circulated the hot dry air inside the dryer, and the exhaust mode emitted the hot humid air outside the dryer. An air vent was installed on the upper part of the dryer, and it was opened or closed by the mode of (b) and (c). Two valves (top and bottom) were installed to open and close the air flow between hot air supply chamber and drying chamber.

Figure 2 shows the algorithm for the internal circulation and exhaust of the hot air. Drying time, temperature, and weight value for three different modes were determined

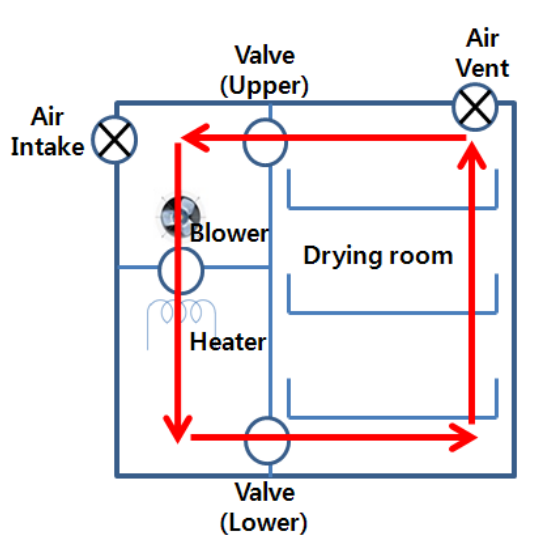

(a) Internal circulation mode

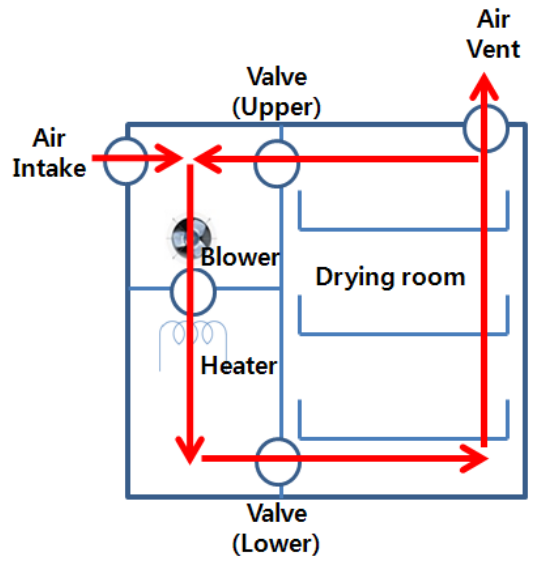

(b) Continuous exhaust mode

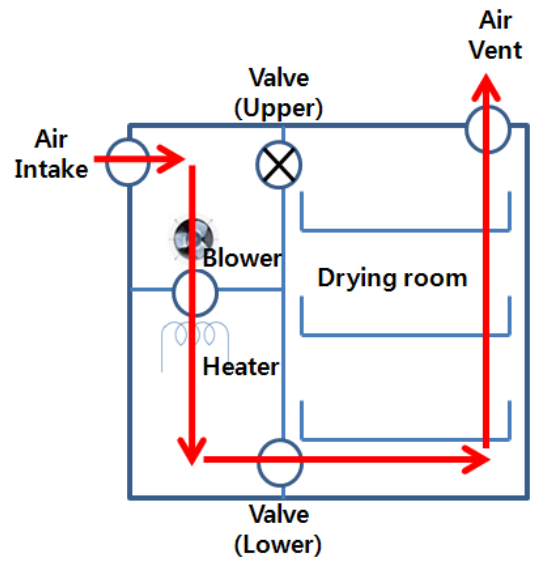

(c) Periodic exhaust mode

Figure 1. Structure of the electric dryer. 


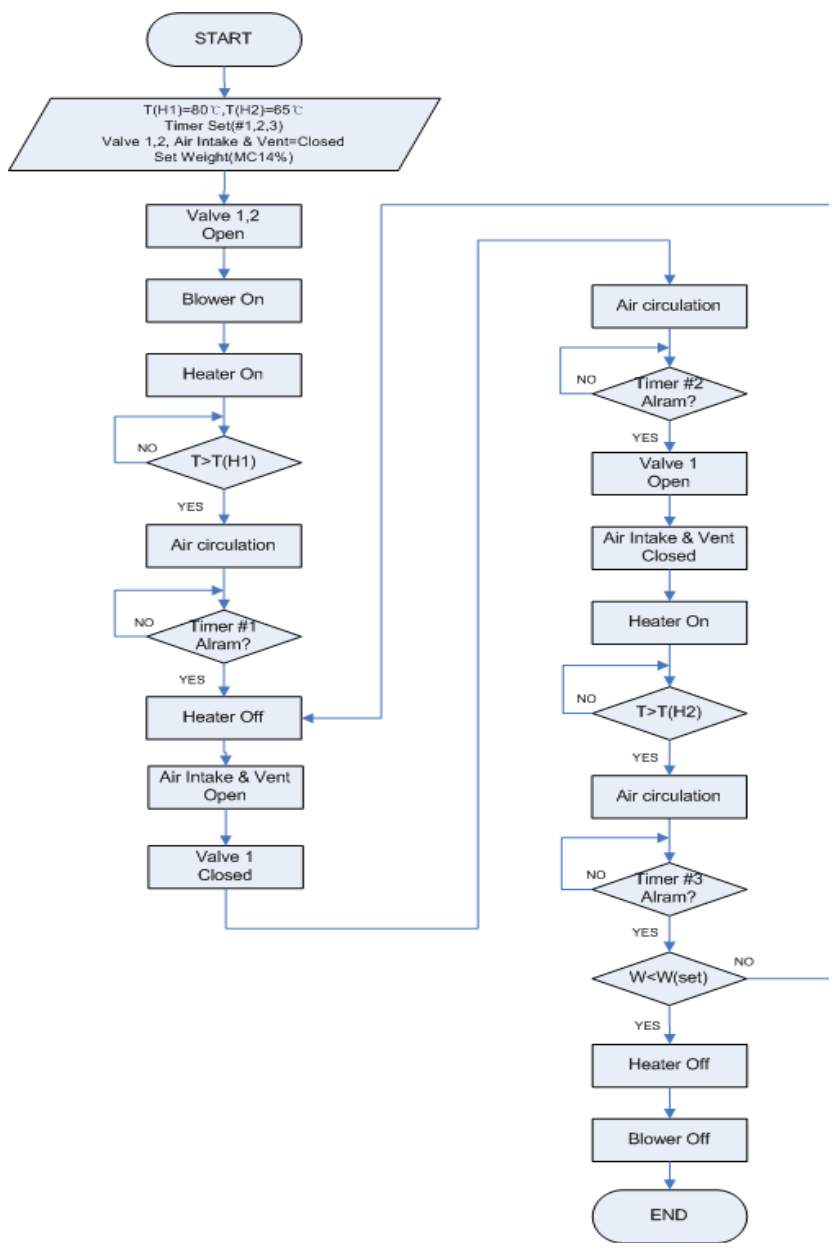

Figure 2. Algorithm for the internal circulation and exhaust of the hot air.

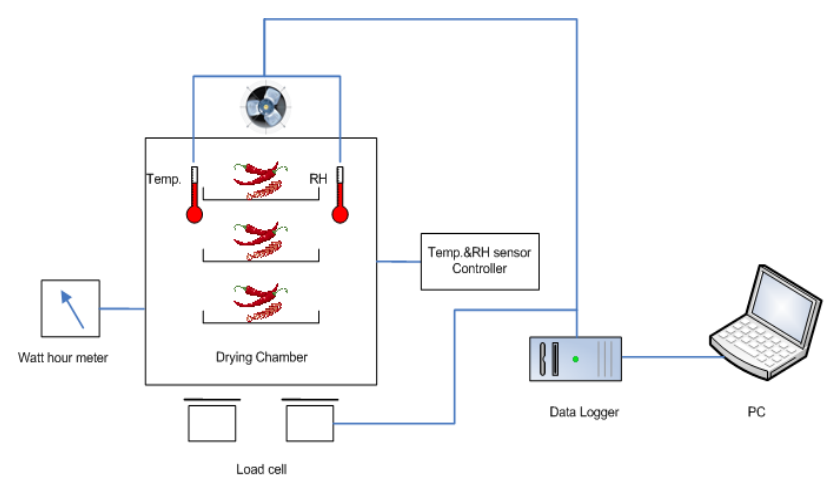

Figure 3. Schematic diagram illustrating measurement and storage of the data.

to control the drying conditions. After switching the heater on and off at the preset time (timer \#1), the exhaust time was set (timer \#2) with opening the valve. Subsequently, the drying initiated with closing the valve for the determined temperature of the hot air and the time for internal circulation (timer \#3). The drying completed

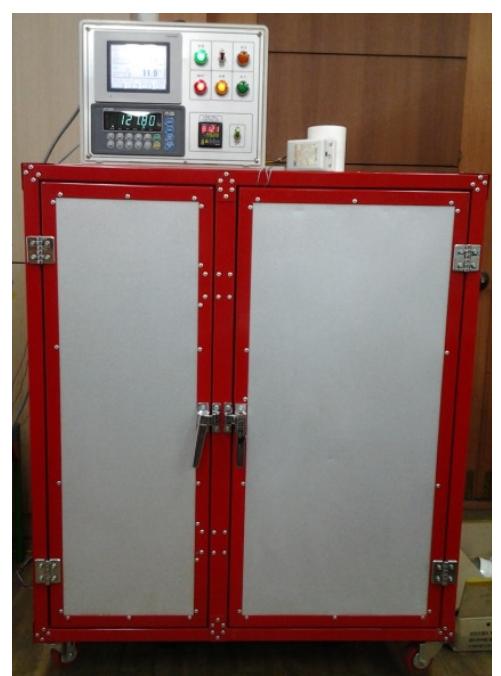

(a) Outside
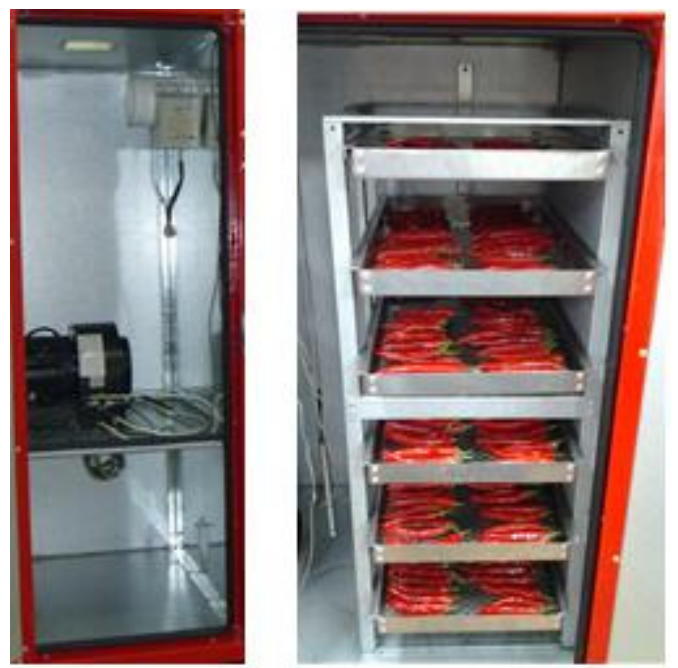

(b) Inside

Figure 4. Inside and outside of the dryer.

when reaching the preset weight value.

The internal dimensions of the drying chamber were $505 \mathrm{~mm}^{*} 645 \mathrm{~mm}^{*} 940 \mathrm{~mm}$ (width * depth * height). Combustion chamber located on the left of the drying chamber had a blowing fan (LD-B 150, 200W, LD INC, Korea) and a $2 \mathrm{~kW}$ heater, and the drying chamber had two valves (top and bottom). Both combustion chamber and drying chamber had a valve (top) for air flow from inside to outside. Exhaust time was determined using the volume of the drying chamber $\left(0.302 \mathrm{~m}^{3}\right)$ and flow rate of exhausted air $\left(0.418 \mathrm{~m}^{3} / \mathrm{min}\right)$.

Figure 3 shows the schematic diagram illustrating measurement and storage of the data. The inside temperature, relative humidity of the drying chamber, 
and changes of weight value of the red peppers were measured (IW2S1 - 150FE, Satorius, Germany), and the data was stored (34970A, Agilent, USA).

Figure 4 shows the inside and outside of the dryer. A control device (TEMI 850, Samwontech, Korea) was attached on top of the dryer to control the drying conditions. And the dryer was composed of a combustion chamber with a fan and heater (Figure 4a) and a drying chamber (Figure 4b).

\section{Drying methods}

Continuous exhaust mode following heating and periodic exhaust mode following heating were applied. Periodic exhaust mode repeated heating and exhaust.

Table 1 show each mode applied in this study. Conventional drying method used continuous exhaust mode following heating ( $\mathrm{T}-1)$, therefore, the red peppers were dried to $14 \%$ of average moisture content with four hours heating and at $65^{\circ} \mathrm{C}$ of exhausting and drying.

After four hours heating with $80^{\circ} \mathrm{C}$, drying process continued with periodic exhaust mode of $65^{\circ} \mathrm{C}$ until reaching the target moisture content.

Conditions of E-1, E-3, and E-6 (G-1) were experimented with exhaust times of 20 minutes, two minutes, and one minute in order to examine the drying characteristics depending on exhaust time.
In order to examine drying characteristics based on heating time, conditions of E-1 and E2 (G-2) and E- 6 and E-7 (G-3) were experimented. 20 minutes of the exhaust time went with 40 minutes and 70 minutes of heating, and one minute of exhaust time went with 30 minutes and 22 minutes of heating.

Conditions of E-3, E-4, E-5, and E-8 (G-4) were experimented to examine drying characteristics depending on exhaust cycle. Each exhaust cycle was set at 40 minutes, 40 minutes $\rightarrow 55$ minutes $\rightarrow 70$ minutes, 40 minutes $\rightarrow 50$ minutes $\rightarrow 60$ minutes $\rightarrow 70$ minutes, and 22 minutes $\rightarrow 42$ minutes.

\section{Drying modeling of red peppers}

Page model as in equation (1) was used to examine drying model for red peppers. Constant values A and B were obtained through non-linear regression analysis, and the results were verified (SAS, 2010).

$$
M=\exp \left(-A t^{B}\right)
$$

Where $M$ : average moisture content (decimal) during time $t$

Table 1. Drying conditions of conventional and cyclic exhaust drying methods

\begin{tabular}{|c|c|c|c|c|c|c|c|c|}
\hline & \multirow{3}{*}{ No. } & & \multirow{2}{*}{\multicolumn{2}{|c|}{ Heating with internal circulation }} & \multirow{3}{*}{$\begin{array}{c}\text { Exhaust } \\
\text { Duration (min) }\end{array}$} & \multicolumn{3}{|c|}{ Drying with cyclic Exhaust } \\
\hline & & & & & & \multicolumn{2}{|c|}{ Heating with internal circulation } & \multirow{2}{*}{$\begin{array}{c}\text { Exhaust } \\
\text { Duration (min }\end{array}$} \\
\hline & & & Temp. $\left({ }^{\circ} \mathrm{C}\right)$ & Duration (hr) & & Temp. $\left({ }^{\circ} \mathrm{C}\right)$ & Duration (min) & \\
\hline \multicolumn{3}{|c|}{$\mathrm{T} 1$} & 80 & 4 & 2 & 65 & - & - \\
\hline \multirow{3}{*}{ G-1 } & & E 1 & 80 & 4 & 20 & 65 & 40 & 20 \\
\hline & & E 3 & 80 & 4 & 2 & 65 & 40 & 2 \\
\hline & & E 6 & 80 & 4 & 2 & 65 & 30 & 1 \\
\hline \multirow{2}{*}{ G-2 } & & E 1 & 80 & 4 & 20 & 65 & 40 & 20 \\
\hline & & E 2 & 80 & 4 & 20 & 65 & 70 & 20 \\
\hline \multirow{2}{*}{ G-3 } & & E 6 & 80 & 4 & 2 & 65 & 30 & 1 \\
\hline & & E 7 & 80 & 4 & 2 & 65 & 22 & 1 \\
\hline \multirow{10}{*}{ G-4 } & & E 3 & 80 & 4 & 2 & 65 & 40 & 2 \\
\hline & & \multirow{3}{*}{ E 4} & \multirow{3}{*}{80} & \multirow{3}{*}{4} & \multirow{3}{*}{2} & 65 & 40 & 2 \\
\hline & & & & & & 65 & 55 & 2 \\
\hline & & & & & & 65 & 70 & 2 \\
\hline & & \multirow{4}{*}{ E 5} & \multirow{4}{*}{80} & \multirow{4}{*}{4} & \multirow{4}{*}{2} & 65 & 40 & 2 \\
\hline & & & & & & 65 & 50 & 2 \\
\hline & & & & & & 65 & 60 & 2 \\
\hline & & & & & & 65 & 70 & 2 \\
\hline & & \multirow{2}{*}{ E 8} & \multirow{2}{*}{80} & \multirow{2}{*}{4} & \multirow{2}{*}{2} & 65 & 22 & 1 \\
\hline & & & & & & 65 & 42 & 1 \\
\hline
\end{tabular}




$$
M=\frac{M(t)-M_{e}}{M_{o}-M_{e}}
$$

Where $M(t)$ : moisture content based on dry weight during time $t$

$M_{o} \quad$ : initial moisture content (decimal) based on dry weight

$M_{e} \quad$ : equilibrium moisture content (decimal)

$t \quad$ : drying time (hr)

$A, B$ : drying constant

\section{Measurement of required energy for drying}

Specific energy consumption (SEC), water removal rate (WRR), ratio of dry (ROD), and drying capacity (DC) were used to evaluate the required energy depending on drying methods. Following equations (2) (5) were used for the calculation.

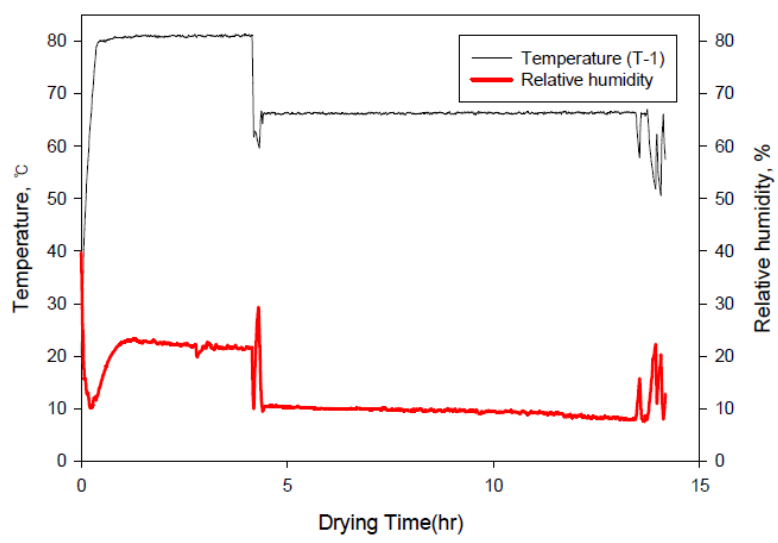

Figure 5. Changes of temperature and relative humidity in the drying chamber by $\mathrm{T}-1$.

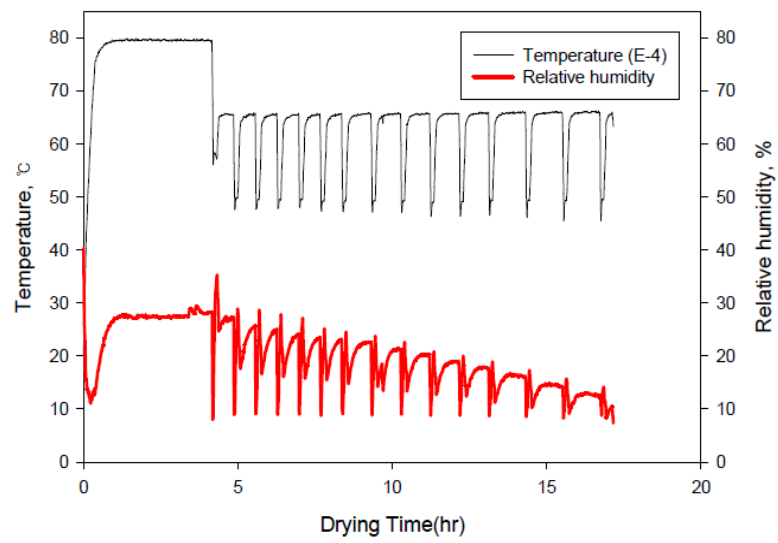

Figure 6. Changes of temperature and relative humidity in the drying chamber by E-4.

$$
\begin{aligned}
& S E C-\frac{P}{\Delta M}[M J / k g-\text { moisture }] \\
& W R R=\frac{\triangle M}{t}[\mathrm{~kg} / \mathrm{hr}] \\
& R O D=\frac{\triangle M C}{t}[\% / \mathrm{hr}] \\
& D C=\frac{M_{P}}{t}[\mathrm{~kg} / \mathrm{hr}]
\end{aligned}
$$

Where $\mathrm{P} \quad$ : total required energy (MJ)

$\triangle M$ : weight of removed moisture $(\mathrm{kg})$

$\triangle M C$ : changes in moisture content (\%)

$M_{P} \quad$ : weight of red peppers $(\mathrm{kg})$

$t \quad$ : drying time (hr)

\section{Measurement of components in red peppers}

Capsaicin, color, and sugar content were measured to evaluate the quality of dried red peppers based on drying methods. Capsaicin and sugar content were measured by HPLC (Hoffman, 1983), and the average of ASTA color value was obtained by spectroscopic analysis (Hong, 1999) using three replications. One-way ANOVA was examined to find out the relationship between the capsaicin, sugar content, and color based on drying methods. If significant relationship was observed, Duncan's post-validation was performed (SPSS, 2012).

\section{Results and Discussion}

\section{Changes of temperature and relative humidity based on drying methods}

Figures 5 and 6 show the changes of temperature and relative humidity based on drying time. Figure 5 represents the continuous exhaust mode (T-1), and Figure 6 represents one condition of the periodic exhaust mode (E-4). Inside temperature and relative humidity of the drying chamber descended with exhausting, and both ascended with heating. In addition, the relative humidity ascended with drying time.

\section{Drying model based on drying methods}

Drying constants A and B of the dried red peppers were calculated using Page model, and the results were 
Nam et al. Effects of Drying Methods Based on Exhaust Cycle and Time on the Quality and Drying of Red Peppers Journal of Biosystems Engineering • Vol. 39, No. 2, $2014 \cdot$ www.jbeng.org

Table 2. Coefficients of Page equations resulted from test drying with various heating conditions

\begin{tabular}{cccccc} 
Method of Drying & A & B & $R^{2}$ & F value & P value \\
T 1 & 0.1034 & 1.2185 & 0.9945 & 13235.7 & $<.0001$ \\
E 1 & 0.2004 & 0.8671 & 0.9974 & 5529.41 & $<0.0001$ \\
E 2 & 0.2239 & 0.8717 & 0.9975 & 5114.00 & $<0.0001$ \\
E 3 & 0.1114 & 1.1158 & 0.9984 & 4731.08 & $<0.0001$ \\
E 4 & 0.1076 & 1.1406 & 0.9977 & 5063.98 & $<0.0001$ \\
E 5 & 0.1111 & 1.1182 & 0.9983 & 11236.4 & $<0.0001$ \\
E 6 & 0.1233 & 1.1185 & 0.9983 & 4927.61 & $<0.0001$ \\
E 7 & 0.0900 & 1.2411 & 0.9935 & 5693.03 & $<0.0001$ \\
E 8 & 0.1018 & 1.2271 & 0.9941 & 2921.19 & $<0.0001$ \\
\hline
\end{tabular}

Table 3. Test results of drying with various heating and exhaust time of humid air

\begin{tabular}{ccccccccccc} 
Test designation & E 1 & E 2 & E 3 & E 4 & E 5 & E 6 & E 7 & E 8 & T 1 \\
Amount of electricity (kWh) & 25.50 & 17.16 & 13.04 & 11.42 & 12.96 & 11.30 & 10.92 & 10.83 & 15.70 \\
Drying time (hr) & 28.69 & 25.14 & 22.80 & 22.11 & 22.93 & 20.75 & 19.78 & 18.50 & 18.40 \\
\hline SEC (MJ/kg) & 29.77 & 20.22 & 15.07 & 13.29 & 15.28 & 13.24 & 12.87 & 12.69 & 18.39 \\
WRR (kg/hr) & 0.1071 & 0.1225 & 0.1344 & 0.1388 & 0.1343 & 0.1481 & 0.1556 & 0.1662 & 0.1671 \\
ROD (\%/hr) & 2.46 & 2.80 & 3.09 & 3.19 & 3.07 & 3.40 & 3.56 & 3.81 & 3.83 \\
DC (kg/hr) & 0.1311 & 0.1482 & 0.1666 & 0.1707 & 0.1625 & 0.1807 & 0.1884 & 0.2027 & 0.2038 \\
\hline
\end{tabular}

presented in Table 2. Smaller value of A and larger value of $\mathrm{B}$ tended to reduce drying time. $\mathrm{R}^{2}$ value was over 0.993 which represents model equation was consistent with experimental data. $F$ value was in the ranges of 2.921 $\sim$ 5693.03, and $P$ value was under 0.0001 which showed high significance level.

\section{Drying characteristics based on drying methods}

The amount of electricity, drying time, specific energy consumption (SEC), water removal rate (WRR), ratio of dry (ROD), and drying capacity (DC) were produced from the calculation of the experimental data (Table 3). Using the data from Tables 2 and 3, the drying characteristics based on exhaust cycle and time are as follows:

\section{Drying characteristics based on exhaust time ( $G$-1)}

Figure 7 shows the changes of moisture content based on drying times of E-1, E-3, E-6, and T-1. Drying times were increased to 20.75 hours, 22.80 hours, and 28.69 hours at E-6, E-3, and E-1 conditions, respectively as the exhaust time was increased. In addition, specific energy consumption was increased to $13.24 \mathrm{MJ} / \mathrm{kg}, 15.07 \mathrm{MJ} / \mathrm{kg}$, and $29.79 \mathrm{MJ} / \mathrm{kg}$ at E-6, E-3, and E-1 conditions, respectively. E-1 condition with long exhaust time was not an appropriate

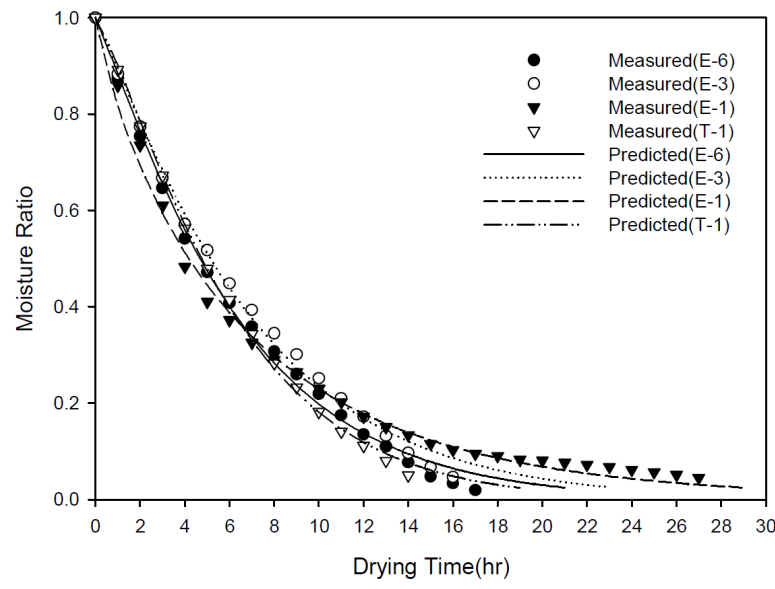

Figure 7. Drying curves at G-1.

method in that it took a lot of time and energy due to the temperature drop. However, conditions of E- 6 and E-3 reduced the required energy by $28 \%$ and $17 \%$ and increased drying time compared with $\mathrm{T} 1$ condition. From the result, short exhaust time is more efficient in terms of energy.

\section{Drying characteristics based on heating time ( $G-2$ and $G-3$ )}

In order to compare the drying characteristics based 
on heating time, changes of moisture content ratio in two different groups (E-1, E-2, T-1 vs. E-7, E-6, T-1) were represented as in Figures 8 and 9.

Experiments (G-2) with conditions of E-1 and E-2 needed more drying time and energy than continuous exhaust mode (T-1) as in Figure 8. Condition of E-1 having short heating time and exhaust cycle was not a suitable drying method in that it needed a lot of drying time and energy for temperature compensation.

Experiments (G-3) with conditions of E-6 and E-7 needed 20.75 hours (E-6) and 19.78 hours (E-7) of drying time which was longer than continuous exhaust mode (T-1) of 18.4 hours. However, specific energy consumption was reduced to $13.24 \mathrm{MJ} / \mathrm{kg}$ (28\%) with E-6 and 12.87 $\mathrm{MJ} / \mathrm{kg}$ (30\%) with E-7 compared to $18.39 \mathrm{MJ} / \mathrm{kg}$ with T-1. In addition, humidity of the chamber with long heating time did not rise after a certain period of time; therefore, drying potential energy decreased and drying time increased. Thus, long heating time was not efficient in terms of drying time and energy.

Drying characteristics based on exhaust cycle ( $G-4)$

Figure 10 shows the changes of moisture content based on drying time of E-3, E-4, E-5, E-8, and T- 1 to compare the drying characteristics based on exhaust cycle.

Drying times of E-3, E-4, and E-5 were longer than that of T-1 when the exhaust time was changed. However, drying time of E- 8 was similar with the one of T- 1 by 18.5 hours due to the short exhaust cycle. The amounts of required energy of E-3, E-4, E-5, and E-8 were 15.07 $\mathrm{MJ} / \mathrm{kg}, 13.29 \mathrm{MJ} / \mathrm{kg}, 15.28 \mathrm{MJ} / \mathrm{kg}$, and $12.69 \mathrm{MJ} / \mathrm{kg}$, respectively. The total energy of E-8 was reduced by $31 \%$ compared to the one of T-1 (18.39 MJ/kg). Therefore, short exhaust cycle was efficient in terms of drying time and energy.

\section{Quality of dried red peppers}

Table 4 shows the capsaicin, color, and sugar content measured in the dried red peppers. Total capsaicinoids was $15.282 \mathrm{mg} / 100 \mathrm{~g}$ with continuous exhaust mode and $11.266 \sim 34.865 \mathrm{mg} / 100 \mathrm{~g}$ with periodic exhaust mode. ASTA value was 51.201 with continuous exhaust mode and $49.380 \sim 80.579$ with periodic exhaust mode. Sugar content was $11.083 \%$ with continuous exhaust mode and 7.733 12.883\% with periodic exhaust mode.

One-way ANOVA using the F-statistic was examined to

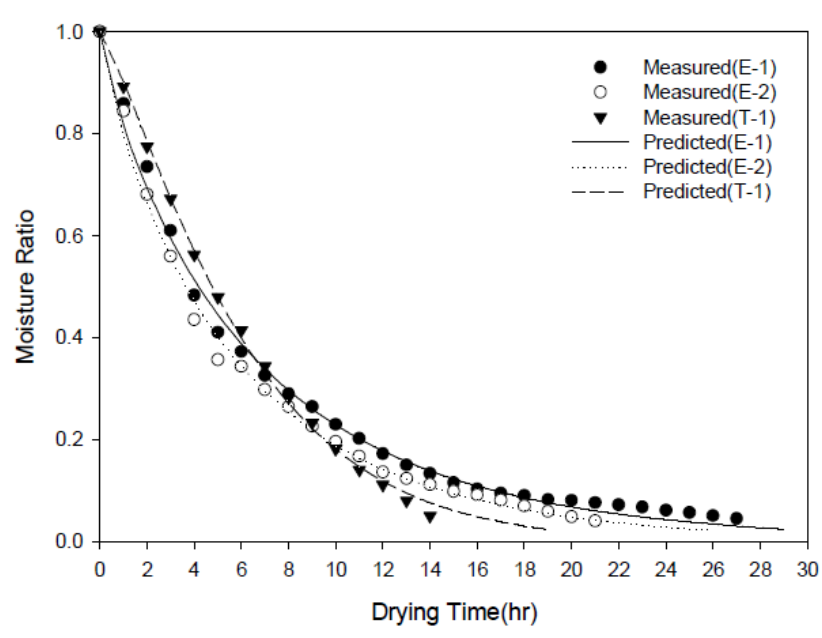

Figure 8. Comparison of drying curves of different heating times with 20 min exhausting time.

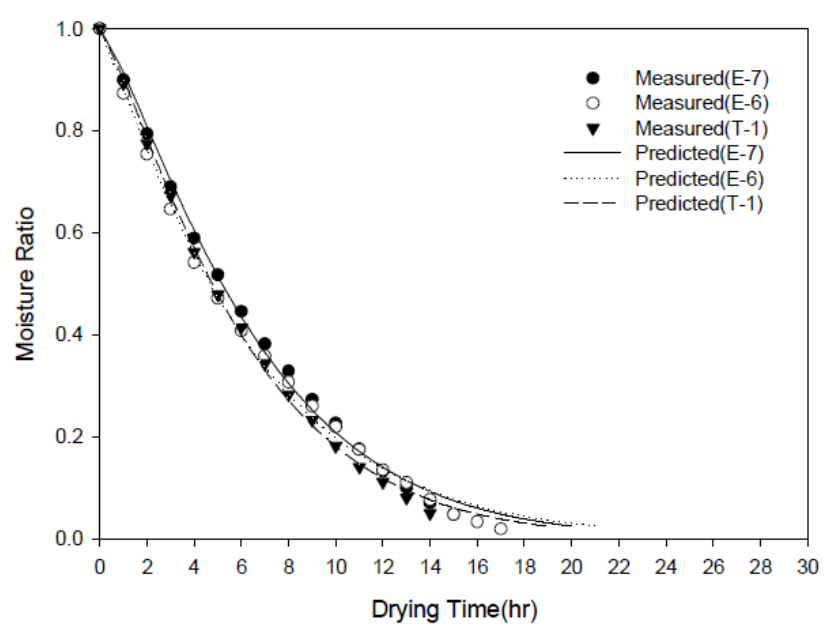

Figure 9. Comparison of drying curves of different heating times with 1 min exhausting time.

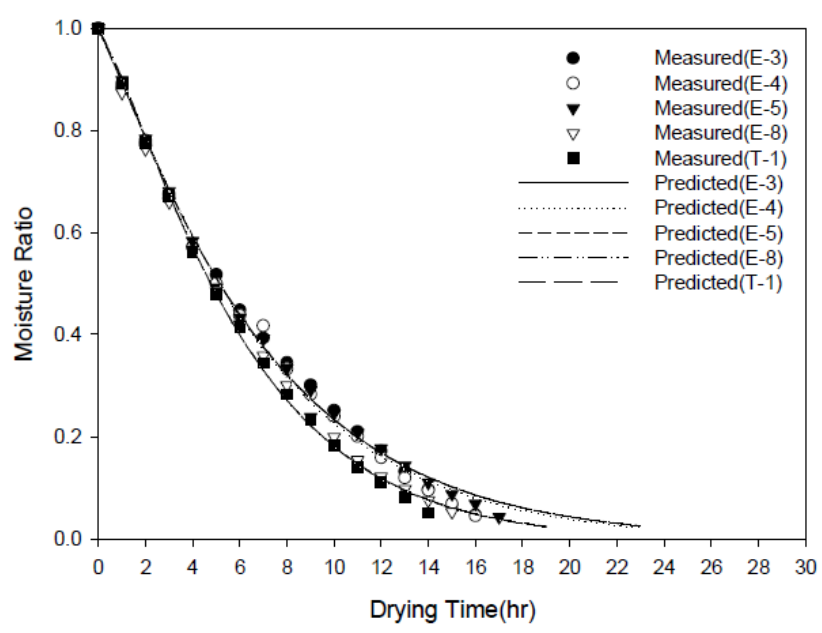

Figure 10. Comparison of drying curves of different heating conditions. 
Nam et al. Effects of Drying Methods Based on Exhaust Cycle and Time on the Quality and Drying of Red Peppers Journal of Biosystems Engineering • Vol. 39, No. 2, $2014 \cdot$ www.jbeng.org

Table 4. Capsaicinoids, ASTA and sugar content in red peppers dried with two different modes

\begin{tabular}{ccccccccc}
$\begin{array}{c}\text { Method of } \\
\text { Drying }\end{array}$ & $\begin{array}{c}\text { Total } \\
\text { capsaicinoids } \\
(\mathrm{mg} / 100 \mathrm{~g})\end{array}$ & $\begin{array}{c}\text { Capsaicin } \\
(\mathrm{mg} / 100 \mathrm{~g})\end{array}$ & $\begin{array}{c}\text { Dihydro } \\
\text { capsaicin } \\
(\mathrm{mg} / 100 \mathrm{~g})\end{array}$ & ASTA & $\begin{array}{c}\text { Total } \\
\text { sugars } \\
(\%)\end{array}$ & $\begin{array}{c}\text { Fructose } \\
(\%)\end{array}$ & $\begin{array}{c}\text { Glucose } \\
(\%)\end{array}$ & $\begin{array}{c}\text { Sucrose } \\
(\%)\end{array}$ \\
\hline T 1 & 15.282 & 10.245 & 5.037 & 51.201 & 11.083 & 5.150 & 4.917 & 1.017 \\
E 1 & 27.470 & 18.024 & 9.446 & 69.274 & 9.567 & 5.183 & 3.483 & 0.900 \\
\hline E 2 & 23.693 & 15.612 & 8.081 & 80.579 & 7.733 & 4.117 & 2.867 & 0.750 \\
E 3 & 26.165 & 16.698 & 9.467 & 49.380 & 12.850 & 5.467 & 6.267 & 1.117 \\
\hline E 4 & 11.266 & 7.444 & 3.822 & 51.933 & 12.300 & 5.400 & 5.867 & 1.033 \\
E 5 & 17.764 & 11.892 & 5.873 & 50.999 & 10.867 & 5.300 & 4.633 & 0.933 \\
\hline E 6 & 26.050 & 16.219 & 9.831 & 69.170 & 12.383 & 5.400 & 5.933 & 1.050 \\
\hline E 7 & 17.393 & 11.162 & 6.231 & 62.211 & 12.883 & 5.633 & 6.267 & 0.983 \\
\hline E 8 & 34.865 & 22.877 & 11.988 & 66.354 & 11.817 & 5.400 & 5.267 & 1.150 \\
\hline
\end{tabular}

Table 5. Results of Duncan's multiple test

\begin{tabular}{|c|c|c|c|c|}
\hline \multicolumn{2}{|c|}{ Method of drying } & Capsaicin & ASTA & Sugar \\
\hline \multirow{4}{*}{ G-1 } & E 6 & $26.0497^{b}$ & $69.0000^{b}$ & $12.4000^{\mathrm{bc}}$ \\
\hline & E 3 & $26.1653^{b}$ & $49.3333^{a}$ & $12.8667^{c}$ \\
\hline & E 1 & $27.4700^{\mathrm{b}}$ & $69.3333^{b}$ & $9.6000^{a}$ \\
\hline & $\mathrm{T} 1$ & $15.2820^{\mathrm{a}}$ & $51.3333^{\mathrm{a}}$ & $11.1000^{\mathrm{ab}}$ \\
\hline \multirow{3}{*}{ G-2 } & E 1 & $27.4700^{\mathrm{C}}$ & $69.3333^{b}$ & $9.6000^{\mathrm{ab}}$ \\
\hline & E 2 & $23.6930^{b}$ & $80.6667^{c}$ & $7.7667^{a}$ \\
\hline & $\mathrm{T} 1$ & $15.2820^{\mathrm{a}}$ & $51.3333^{a}$ & $11.1000^{b}$ \\
\hline \multirow{3}{*}{ G-3 } & E 7 & $17.3927^{\mathrm{a}}$ & $62.3333^{b}$ & $12.9000^{\mathrm{s}}$ \\
\hline & E 6 & $26.0497^{b}$ & $69.0000^{c}$ & $12.4000^{\mathrm{a}}$ \\
\hline & $\mathrm{T} 1$ & $15.2820^{\mathrm{a}}$ & $51.3333^{a}$ & $11.1000^{\mathrm{a}}$ \\
\hline \multirow{5}{*}{ G-4 } & E 3 & $26.1653^{c}$ & $49.3333^{a}$ & $12.8667^{c}$ \\
\hline & E 4 & $11.2660^{\mathrm{a}}$ & $52.0000^{a}$ & $12.3333^{\mathrm{bc}}$ \\
\hline & E 5 & $17.7643^{\mathrm{b}}$ & $51.0000^{\mathrm{a}}$ & $10.9000^{\mathrm{a}}$ \\
\hline & E 8 & $34.8653^{d}$ & $66.3333^{b}$ & $11.8667^{\mathrm{abc}}$ \\
\hline & $\mathrm{T} 1$ & $15.2820^{\mathrm{ab}}$ & $51.3333^{a}$ & $11.1000^{\mathrm{ab}}$ \\
\hline
\end{tabular}

- Means with different letters in a column are significantly different at $p<0.05$ by Duncan's multiple test.

find out the relationship between the capsaicin, sugar content, and color based on drying modes. The results showed that the drying modes had a significant relationship with components; capsaicin, color, and sugar content in order showed a statistically significant difference $(\mathrm{p}<0.05)$. Table 5 shows the results of Duncan's multiple test on experimental groups of G-1, G-2, G-3, and G-4 which analyzed the components with the drying methods.

Values of capsaicin, ASTA, and sugar content were high with short exhaust time at G-1 while the ones of capsaicin and sugar content were high with short heating time at G-2.Values of capsaicin and ASTA were high with long heating time at G-3 and exhaust cycle of 20 40 min at G-4.

\section{Conclusions}

This study modified the conventional drying method exhausting hot air continuously into a drying method changing exhaust cycle and time in order to utilize the drying potential energy of exhausted hot air during drying process. A valve on the vent was controlled according to a preset time to change the exhaust cycle and time. This study analyzed the influence of the drying methods on the drying characteristics, drying energy, and quality of the dried peppers. The results of the study are as follows: 
(1) Drying characteristics based on exhaust time showed that drying time increased with exhaust time, and specific energy consumption was reduced by $28 \%$ from $18.39 \mathrm{MJ} / \mathrm{kg}$ (conventional method) to 13.24 $\mathrm{MJ} / \mathrm{skg}$ when exhaust time was set to one minute.

(2) Drying characteristics based on heating time showed that drying time increased with heating time and specific energy consumption was reduced by $30 \%$ from $18.39 \mathrm{MJ} / \mathrm{kg}$ (conventional method) to 12.87 $\mathrm{MJ} / \mathrm{kg}$ when exhaust time was set to 22 minutes.

(3) Drying characteristics based on exhaust cycle showed that drying time increased with exhaust cycle, and specific energy consumption was reduced by $31 \%$ from 18.39 MJ/kg (conventional method) to 12.69 $\mathrm{MJ} / \mathrm{kg}$ when exhaust time was set to one minute and exhaust cycle was set to 22 minutes before drying and 40 minutes after drying.

(4) The quality of the dried red peppers showed that capsaicin, color, and sugar content were high as $34.87 \mathrm{mg} / 100 \mathrm{~g}, 66.33$, and $11.87 \%$, respectively, when exhaust time was set to one minute and exhaust cycle was set to 22 minutes before drying and 40 minutes after drying.

(5) As a result, drying conditions with short exhaust time such as one minute and short exhaust cycle (not as long as $20 \sim 40$ minutes) were efficient in terms of drying time, required energy and quality of the red peppers.

\section{Conflict of Interest}

The authors have no conflicting financial or other interests.

\section{Acknowledgement}

This research was supported by IPET (Korea Institute of Planning and Evaluation for Technology in Food, Agriculture, Forestry and Fisheries), Ministry for Food, Agriculture, Forestry and Fisheries, Republic of Korea. This research was supported by Kyungpook National University Research Fund, 2012.

\section{References}

Cho, Y. J. 1986. Drying Characteristics and Drying Model of Red Pepper. MS Thesis. Korea, Seoul: Seoul Nat'l University, Department of Agricultural Engineering.

Chung, K. M. and J. M. Hwang. Quality of single harvested red peppers by drying methods. 2003. Korean J. Food Sci. Technol. 35(2): 329-333.

Hoffman, P.G., Lego, M.C. and Galetto, W.G. 1983. Separation and quantitation of red pepper major heat principles by reverse-phase high-pressure liquid chromatography. J. Agric. Food Chem. 31:1326-1330.

Hong, S. H. 1999. The future of red pepper powder industry in Korea. ASTA analytical methods 20.1 Food Ind. Nutr. 4:45-49.

Kim, J. Y., D. H. Keum, J. H. Park, W. W. Kang, Ch. S. Han and Y. K. Lee. 1996. Evaluation of quality of red pepper with variations in drying methods. Korean J. Post-Harvest Sci. Technol. Agri. Products, 3(2): 137-143.

Kim, K. H. and J. K. Chun. 1975. The effects of the hot air drying of red pepper on the quality. Korean J. Food Sci. Technol. 17(2):69-73.

Kim, M. H. 1997. Color development of whole red peppers during drying, Food Engineering 1(3):174-178.

Koh, H. K., Y. J. Cho and W. S. Lee. 1987. Effects of Variations of Drying Conditions on the Rate of Drying and Quality during Red Pepper Drying. Agric. Res. Seoul Nat'l Univ., 12(1):79-88.

Koh, H. K., Y. J. Cho and S. W. Kang. 1990. Application of an Infrared Drying Process for Red Pepper. 15(3):230243.

Koh, H. K. 1998. Development of Drying System for Red Pepper. Annual Report of Research in Agriculture and Life Sciences. 2:70-73.

Ku, K. H., N. Y. Kim, J. B. Park and W. S. Park. 2001. Characteristics of color and pungency in the red pepper for kimchi. Korean J. Food Sci. Technol. 33:231-237.

Lee, W. S., H. K. Koh, S. H. Noh and Y. J. Cho. 1988. A Single Layer Drying Equation for Red Pepper. J. Agric. Sci. 13(2):59-71.

Moon, S. B., D. Y. Choi, J. H. Lee, K. K. Kim and S. Y. Choi. 1999. A Study on the thermal characteristics of cayenne by low temperature vacuum dryer. SAREK 1999(1): 410-414.

Page. C. 1949. Factors influencing the maximum rates of air drying shelled corn in thin layers. MS. Thesis. 
Nam et al. Effects of Drying Methods Based on Exhaust Cycle and Time on the Quality and Drying of Red Peppers Journal of Biosystems Engineering • Vol. 39, No. 2, $2014 \cdot$ www.jbeng.org

Purdue University.

Park, Ch. R. 1975. A study on the influence of drying methods upon the chemical changes in red pepper. $\mathrm{K}$. J. N., 8(4): 167-172.

Park, J. G. 2008. Bio-production Machinery Engineering. CIR, Seoul, Republic of Korea.

Paek, Y., Y. J. Kim, G. C. Kang, Y. S. Ryou. 2002. Heat Recovery System from Chamber of Agricultural Products Dryer. KSAM Conference Proceeding. 7(2).

SAS. 2010. SAS 9.1 User's Guide. SAS Institute Inc., North
Carolina, USA.

SPSS. 2012. SPSS Statistics 19. User's Guide. Chicago, IL: SPSS, Inc.

Yoon, W. M., J. Y. Lee. 2004. Effect of Dying Method on the Quality of Red Pepper(Capsicum annuum var. longum). J. Natural Sciences Pai Chai Univ. 14(1): 139-149.

Yoon, Y. C. and W. M. Suh. 1999. Pepper drying by the heat discharged from heat pump system in greenhouse. KSBEC. Conference 8(2): 204-208. 